Publicado por primera vez en:

Toro, Alfonso de. (2004). "Arte, Literatura y Teatro menor postmoderno: Borges y Pavlovsky", en: Alfonso de Toro (ed.). Estrategias postmodernas y postcoloniales en el teatro latinoamericano actual. Hibridez - Medialidad Cuerpo. (Theorie und Praxis des Theaters, Vol. 11, Frankfurt am Main: Vervuert). p. 443-461. 


\author{
Alfonso de Toro \\ Ibero-Amerikanisches Forschungsseminar \\ Universität Leipzig
}

\title{
ARTE, LITERATURA Y TEATRO MENOR POSTMODERNO: BORGES Y PAVLOVSKY
}

\begin{abstract}
L'autre procède à force de sécheresse et de sobrieté, de pauvreté voulue, poussant la déterritorialisation jusqu'à ce que ne subsistent plus que des intensités.

$[\ldots]$

Combien de gens aujourd'hui vivent dans une langue qui n'est pas la leur?

$[\ldots]$

[...] comment arracher à sa propre langue une littérature mineure, capable de creuser le langage, et de le faire filer suivant une ligne révolutionnaire sobre? Comme devenir le nomade et l'immigré et le tzigane de sa propre langue?

$[\ldots]$

Mais, ce qui est intéressant encore, c'est la possibilité de faire de sa propre langue, à supposer qu'elle soit unique, qu'elle soit une langue majeure ou l'ait été, un usage mineur. Être dans sa propre langue comme un étranger [...]

$[\ldots]$

Wörterflucht. Se servir du polylinguisme dans sa propre langue, faire de celle-ci un usage mineur ou intensif, opposer le caractère opprimé de cette langue à son caractère oppresseur, trouver les points de non-culture et de sous-développement, les zones de tiersmonde linguistiques par où une langue s'échappe, un animal se greffe, un agencement se branche.
\end{abstract}

(Deleuze/Guattari 1975: 35, 48, 49)

\section{LA PRODUCCIÓN PERIFÉRICA Y EL “TEATRO MENOR"}

El teatro de Eduardo Pavlovsky, en el transcurso de toda su obra, ha sido simplemente un teatro que se ha ido y se va a las orillas, a la periferia, un teatro dentro de lo que podemos llamar - parafraseando a Deleuze/Guattari- "teatro menor" (vid. Deleuze/ Guattari 1975), para poder allí, libre de condicionamientos externos, producir un teatro que llamaría orgánico, esto es, un teatro en el que la representación sea al final el logro natural de una búsqueda, de una transformación, de una acto de creación que

Este trabajo fue presentado por mí con el título "El teatro menor postmoderno: Eduardo Pavlovsky o el "Borges" y el "Bacon" del teatro: de la periferia al centro" por invitación de Eduardo Pavlovsky en su "Instituto de Psicodrama" en Buenos Aires el 06 de julio de 2000. 
cada vez que se representa sea capaz de abrir nuevas entradas y salidas tanto en los actores mismos como en los espectadores o en los lectores de esta obra. De esta forma la obra de Pavlovsky se establece como una de las manifestaciones más exitosas de la producción teatral en el concierto internacional del teatro. Pavlovsky se encuentra en Argentina en muy buena compañía y tradición: no olvidemos que Borges fue un autor de las orillas por mucho tiempo y desde allí se impuso en el centro como lo estamos experimentando cada vez más claramente.

Pero profundicemos un momento esta categoría de 'lo menor' y esta relación discursiva, estética y de pensamiento entre Pavlovsky y Borges. Tanto Borges como Pavlovsky trabajaban en las 'orillas' para descentrar los cánones establecidos en el pensamiento, en la cultura, en la literatura y el teatro en Buenos Aires y fundar así su propia concepción literaria o teatral, lo cual es algo prácticamente típico de ambos autores en Buenos Aires.

Esta teoría de producir una literatura, un teatro y una estética en los márgenes tiene su respaldo en presedentes literarios y teatrales, por ejemplo, en Baudelaire, DeQuincy, Kafka, en Jarry y Artaud, Beckett e Ionesco, y en el nivel de la teoría y terminología en Deleuze/Guattari (1975: especialmente pp. 29-50) quienes la desarrollan en forma maestra partiendo de Kafka, cuyo trabajo y operación literario-cultural denominan "littérature mineure". Además, cabe indicar que tanto Borges como Pavlovsky no solamente proceden así a nivel local, sino frente a la llamada literatura universal y frente a muchos autores y/o a filósofos que no se encuentran en los cánones establecidos.

Muchos autores que Borges aprecia no gozan, ni en las enciclopedias ni en las historias de la literatura, del lugar que él les otorga. Borges trabaja, pues, muchos campos marginales (también en el sentido de que no están en la conyuntura literaria de la época) y autores muy discutidos. El gusto de Borges es algo muy particular de él y muchos de los autores de su elección gozan de un prestigio particular, pero representan "casos especiales" en el oficio literario y en el ámbito intelectual ya que se mueven en campos limítrofes entre literatura, ensayo, filosofía, religión, esotérica, psicología, etc. El criterio con el que Borges calificaba la literatura como buena o mala era su propio gusto o las preferencias que compartía con otros autores (A. de Toro 1992: 148; 2001).

Pavlovsky traba sus relaciones transdramáticas con autores que, habiendo llegado a ser "clásicos", han representado en su momento una fuerte ruptura en los modelos teatrales y representacionales -como Pinter, Artaud, Beckett, Adamov, Arrabal o Ionesco, Dario Fo, Kantor y Wilson, O’Ocasey y Pirandello- o como Deleuze/ Guattari en la filosofía, Bacon en la pintura o Philippe Glass en la música.

Otro aspecto que contribuye a la construcción de un "arte menor" en Borges es evidentemente la enciclopedia. En una entrevista, Borges declara que su género preferido es la enciclopedia por su carácter descentrado y nómada. Este 'género', como Borges denomina a la enciclopedia, le permite una enorme libertad de leer y apoderarse fragmentariamente de textos que luego deconstruye, desplaza o "transmuta" suplementariamente. La enciclopedia constituye su topografía del mundo, es su mun- 
do, forma la topografía de su propia patria. De allí que Borges reúna en un mismo lugar la literatura local y la extranjera deconstruyéndolas en un mismo acto de lectura. Borges trae el llamado centro a la periferia y sitúa la periferia en el centro (vid. A. de Toro 1995: 11-45). Estas dicotomías binaristas pierden su razón de ser y la genuina universalidad de Borges radica en que hace una "literatura menor", un suplemento único.

Similar es la actitud de Pavlovsky frente al teatro: para él el teatro no se divide en regiones ni geográficas ni ideólogicas, sino en material para su quehacer teatral y en sus conceptos estéticos. Ni la literatura europea o norteamericana, ni el teatro europeo o norteamericano son para Borges o para Pavlovsky un relicto de nostalgia, algo extraño, al contrario, lo extraño lo constituyen en un comienzo un tipo de literatura argentina y un tipo de teatro argentino muy difundido -lo cual tanto Borges como Pavlovsky reinventan-; Pavlovsky habla de la estética de la multiplicidad.

Esta tensión de culturas no se presenta ni para Borges ni para Pavlovsky como conflicto, sino que la reintegran en una "literatura/teatro menor", una reinvención 'mímicra' desde los márgenes (=desviación del canon) o la creación de un 'Oriente'. Tanto la creación de Borges como la de Pavlovsky no es el resultado de un conflicto cultural, sino primero el resultado de una práctica literaria o teatral acuñada por la multiplicidad. Borges y Pavlovsky viajan a través de los diversos sistemas y mundos que son el resultado de una actitud transcultural y de un concepto de literatura/teatro que se basa en un epistema de la altaridad que constituyen el lugar semiótico de sus poéticas y prácticas, creando constantemente el 'Oriente' a través de des- y reterritorialización ${ }^{1}$. De allí podemos quizás comprender mejor aquella fórmula de Borges

1 Como en castellano ambos términos, el de 'Unterschied' y el de 'différance', se traducen generalmente como 'diferencia', se ofrece la posibilidad de emplear el término de 'Unterschied' en la concepción de Hegel (1801/1981) como 'diferencia', es decir, como una diferencia en base a oposiciones binarias dentro de un modelo de construcciones de tipo dualista, y el de 'différance' de Derrida como 'diferancia', contra el dualismo y el logocentrismo, como término nómada, descentrado, contaminante, diseminante. En castellano se emplea comúnmente el término 'alteridad' en la antropología, sociología e historia como una marca binarista, distintiva del otro, es decir, como exclusión o isolación, marginalización del otro. Bajo 'altaridad', por el contrario, queremos entender la tensión irreductible de las etnias y culturas, el estar 'entre medio', en un constante proceso de redefinición del lugar cultural y de la identidad. Altaridad es un concepto (que en la filosofía se puede traducir como 'diferancia', 'rizoma', 'hibridez'...) que empleamos como una estrategia socio-político-cultural. Con respecto al término 'altaridad' y a su empleo en la filosofía y en la teoría de la cultura, cfr. Taylor (1987) y F. de Toro (1995). El término de mímicra lo usa Bhabha (1994: 85-92) en el sentido lacaniano (Lacan 1978: 97-111) -como indicábamos más arriba- y es plenamente correspondiente no solamente con el de 'glissement' o de 'altérité' (1966: 249-289, en esp. 260, 283-284) del mismo autor, sino a la vez equivalente con los de 'dissemination' y de 'trace' de Derrida (1967, 1968, 1972) y con aquel de 'rhizôme' y 'territorialization'/ 'deterritorialization' de Deleuze/Guattari (1976). Mientras Bhabha formula la mímicra "as a subject a difference that is almost the same, but not quite" (1994: 86 passim), Lacan (1966: 284) la formula como y en el sentido de altaridad -al contrario de la posición unificatoria de 
que reza: "[...] el problema del escritor argentino y la tradición [...] se trata de una apariencia, de un simulacro, de un seudoproblema" (OC I: 267) ${ }^{2}$.

Borges y Pavlovsky no han sido ninguno en su medida creadores de las 'orillas' en el sentido de "un marginal en el centro, un cosmopolita en los márgenes" (Sarlo 1993/1995: 18) (en el mejor de los casos geográficamente), sino un escritor/un dramaturgo de "arte menor", esto es, uno que emprende una desterritorialización y una reterritorialización rizomática de la literatura o del teatro. Esto es, Borges y Pavlovsky trascienden su lugar de trabajo -como Kafka en las palabras de Borges ${ }^{3}-\mathrm{y}$ por esto ambos son ejemplos perfectos de un "arte menor".

Quisiera a continuación tomar una ruta anecdótico-biografista y mostrar que a Borges y a Pavlovsky desde un principio se les presenta la literatura y el teatro como un problema no de imitación, sino de altaridad donde éste emplea una escritura mímicra y descentrada, suplementaria, desplazada como método de reinventar su mundo literario o teatral en un 'Oriente' semiótico-epistemológico, ya sea el de Buenos Aires, el europeo, el de la enciclopedia o el del teatro universal, para así crear una nueva forma de lectura, de performancia, de escritura, de representación, en fin, de hacer una literatura y teatro diferente y hacer lo suyo, propio, una literatura y un teatro que debe estar siempre en camino, que combaten la inmovilidad, la automatización. Se trata de una literatura, de un teatro "más allá", en la llanura, en el

Freud ("Wo Es war, soll Ich werden"), en el sentido de 'Versöhnung', es decir, de 'reconciliación'- como “un degré second de l'altérité" o como:

“[...] le travesti, le camouflage, l'intimidation. [...]. Le mimétisme donne à voir quelque chose en tant qu'il est distinct de ce qu'on pourrait appeler un lui-même qui est derrière. L'effet du mimétisme est camouflage, au sens proprement technique. Il ne s'agit pas de se mettre en accord avec le fond mais, sur un fond bigarré, de se faire bigarrure exactement comme opère la technique du camouflage dans les opérations de guerre humaine". (Lacan 1964/1973: 92)

El término de 'mimétisme' de Lacan no se debe entender como 'mimesis', sino como mímicra. Así es traducido también en alemán: "Die Mimikry gibt insofern etwas zu sehen, als sie von dem, was man ein »es-selbst« nennen könnte, das dahinter wäre, sich unterscheidet”; y en Derrida (1972: 30) se define este fenómeno como:

Nous savons, disions-nous plus haut. Or nous savons ici quelque chose qui n'est plus rien, et d'un savoir dont la forme ne se laisse plus reconnaître sous ce vieux titre.

2 Con las $O C$ nos referimos a las Obras Completas de Borges, los números romanos corresponden a los diferentes volúmenes de las mismas.

3 En un ensayo como homenaje a Kafka en El País, Borges se expresa de la siguiente forma:

Kafka en cambio tiene textos, sobre todo en sus cuentos, donde se establece algo eterno. A Kafka podemos leerlo y pensar que sus fábulas son tan antiguas como la historia, que esos sueños fueron soñados por hombres de otra época sin necesidad de vincularlos a Alemania o a Arabia. El hecho de haber escrito un texto que trasciende el momento en que se escribió es notable. Se puede pensar que se redactó en Persia o en China y ahí está su valor. (1983: 3) 
desierto de lo no automatizado, de una literatura y de un teatro en constante desautomatización.

El término de 'orilla' de Borges, más bien metafórico, y la posicionalidad de Pavlovsky de hacer otro teatro, lo quisiera definir no como la orilla excluida, sino como fisura (Spalt y no Riß, sino clivage), como Rückfaltung (reploiement/repliegue/dobladura), Aufpfropfung (greffer/injerto) donde se reúne lo uno y lo otro, donde en un plano se negocian las tensiones de la diferencia, una especie de cuadro de Escher o de una superficie de Möbius, un plano pluridimensional, abierto, sin centro, simultáneo. 'Orilla'/'fisura' como altaridad, como 'en medio' ('in-between'), como mímicra en el sentido que le dan Lacan (1973: 85-96) y Bhabha (1994) a este término ${ }^{4}$, como 'pli' ('Falte', 'Knick', 'Zwischenlage'; 'arruga', 'pliegue', 'dobladura', 'intercalación'; Deleuze 1988).

Borges y Pavlovsky proceden como lo hacen Baudelaire en la poesía o Balzac, los hermanos Goncourt en la novela, Beckett e Ionesco en el teatro: "deslimitan" los temas literarios y teatrales, los géneros y el concepto de literatura y de teatralidad en general, "deslimitan" la tradición literaria y dramático-teatral en Argentina y con esto el concepto de lectura, escritura y representación pasan a ser un acto semiótico equivalente. A comienzos de siglo, cuando Borges regresa de Europa, la literatura se encontraba en Argentina entre un criollismo nacionalista y un modernismo imitador y reproductor de vanguardias europeas. Así como la literatura europea llegando al límite de las posibilidades de representación por el agotamiento del realismo se vuelca en la teoría del inconsciente de Freud, abriéndosele nuevas posibilidades e incursiones que prescindieran del 'effet de réel', Borges capta ese límite tanto en la literatura europea del siglo XIX y de las vanguardias del siglo XX como en Argentina. Pavlovsky a su vez se encuentra frente a un teatro altamente realista, brechtiano y política e ideológicamente prefigurado, comprometido y subyugado a la mimesis o altamente reproductivo y extranjerizante. A esa literatura y a ese teatro le falta su "patois". Por esto, Borges y Pavlovsky están tratando formas de altaridad de tipo general (universal) y no tomando una actitud periférica desde la perspectiva del centro. A Borges y a Pavlovsky no se les presenta el fenómeno de la orilla en forma de exclusión: ambos se apoderan de su contexto rioplatense con la misma voracidad y naturalidad con la que se apoderaron de las literaturas, dramas y teatros ingleses, alemanes, escandinavos, franceses u otros. Borges y Pavlovsky están haciendo $s u$ 'Oriente', implantando su mirada, su lectura, su representación, su cuerpo, su desierto, la literatura, el teatro por hacerse, su página no escrita, un espacio escénico no habitado. 'Oriente' es en Borges y Pavlovsky el estar siempre fuera y dentro del territorio, el estar plegado, "en medio", intercalado entre todas las posibilidades. Borges y Pavlovsky no inventan el objeto literario, y podríamos afirmar parafraseando el concepto de 'pli' de Deleuze (1988: 5ss.) que Borges y Pavlovsky recogen todos los

$4 \quad \mathrm{Al}$ respecto de estos términos vid. A. de Toro (1996: 80-81; 2001), vid. también más arriba la nota 1 . 
“[...] plis venus d'Orient, les plis grecs, romains, romans, gothiques, classiques ... Mais il courbe et recourbe les plis, les pousse à l'infini, pli sur pli, pli selon pli”.

La mejor prueba de esto es -como apuntan Sarlo y Olea Franco (1993)- que Borges reinventa la orilla, reiventa Palermo, esto es, lo hace literatura, se desprende de la referencia del arrabal y del compadrito para crear el mito literario de Buenos Aires en un momento cuando ese Palermo ya iba desapareciendo (Sarlo 1993/1995: 52, 54), así como Balzac crea el mito de París en la primera mitad del siglo XIX. Pavlovsky integra al boxeador, al atleta (Último Match, Cámara lenta. Historia de una cara), a la burguesía, al terrorista (La Mueca, Cerca), la violencia (Telaraña), el poder y la tortura (El señor Galíndez, Pablo, El señor Laforgue, Potestad), el deseo y el dolor (Paso de Dos, Potestad), habla de la teatralidad y la globalización, de la economía y de la ausencia (Rojos globos rojos, Poroto, La muerte de Margarite Duras). Borges y Pavlovsky realizan una enorme dislocación del canon respectivo en cuanto incluyen, recodificados, campos que estaban excluidos de éste; incluyen al outsider, al discriminado, lo bizarro, lo burdo, lo profano, la Pampa, los suburbios, del almacén, del ring de boxeo, de la buhardilla, y todo esto lo ponen a disposición de una literarización y teatralización que escapa a la imitación o a un criollismo localista-nacionalista como se manifiesta en El tamaño de mi esperanza o como lo declara Pavlovsky:

[...] nuestro teatro está muy lleno, muy influenciado, por las políticas, por la línea dura político-mensajista [...] tengo mis aficiones a un teatro que carece de ese imperialismo de la identidad ("aca nació", "de allá viene", "está tomando mate") como es por lo general el teatro rioplatense. (En: ídem/A. de Toro 1991: 43)

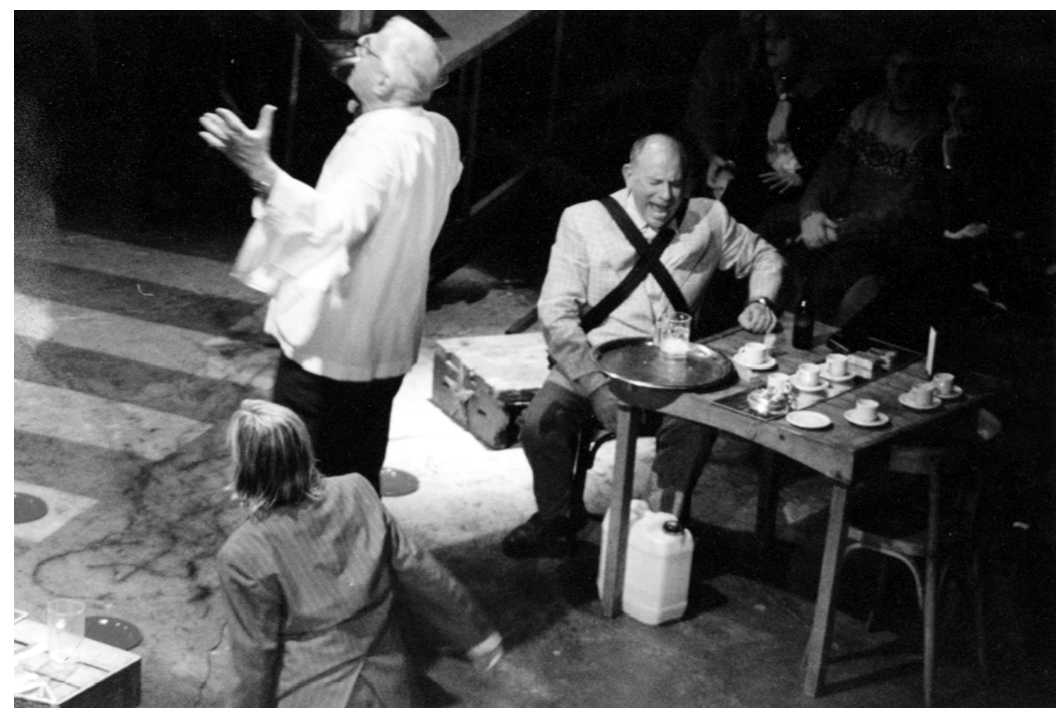

Escena de Poroto (Eduardo Pavlovsky, Susy Evans, Norman Briski)

(C) Foto de Alfonso de Toro 
Borges y Pavlovsky hacen de los márgenes el centro y del centro margen: esto es lo que podemos llamar "hacer Oriente".

"Literatura menor" quiere decir en Borges "escritura, notas sobre libros imaginarios" (OC I: 429): él toma un pre-texto (cfr. de Toro 1992: 145-183; 1994: 5-32) para a su vez construir el suyo que se pierde en la traza de citas y más citas, en una proliferación infinita: "pli sur pli”. Éste es el mensaje que nos hace llegar Borges en muchas de sus obras, por ejemplo, en "Pierre Menard", en "Tlön, Uqbar, Orbis Tertius" o en "El Inmortal" y no una desgarrada identidad cultural. Esta actitud deconstruccionista de Borges frente a toda la literatura no es el resultado de un hecho ontológico o esencialista, el ser argentino, o así como el hecho de vivir en Buenos Aires, tampoco es una conditio del ser latinoamericano, sino una practicada dialogicidad descentrada con diversas culturas; algo que se ha dado en toda la cultura, sin olvidar a los maestros de la altaridad literaria o cultural en general, sociológica y política como Fernando de Rojas, Rabelais, Cervantes, Quevedo, Baudelaire, Mallarmé y Kafka.

Pavlovsky nos habla en este contexto de un "teatro del goce", de un "teatro de la intensidad", de un "teatro de la multiplicidad", de un teatro de la ruptura y subversión como lo es desde un comienzo, pero también en Pablos, Potestad o Paso de Dos: "Mis personajes, muy por el contrario, son ambiguos y denotan una ruptura de la representación” (en: ídem/A. de Toro 1991: 43).

Una concepción de las 'orillas' que se adscribe demasiado al contexto local podría fomentar el peligro de una "exotización" involuntaria de Borges y de Pavlovsky dentro de un tipo de crítica. Por suerte Pavlovsky, y Borges mucho menos, no son "exotizables". Borges y Pavlovsky no crean sobre una tradición precolombina ni sobre una tradición mestiza, sino híbrida. Ellos traen el centro a la periferia y ponen la periferia en el centro: producen su 'Oriente', cubren con nuevos grafemas y representaciones un territorio por habitar.

En un aspecto parecería que la categoría de las 'orillas' describiese la realidad cultural de Borges y de Pavlovsky: si el primero hubiese escrito en inglés o en francés habría sido leído antes. Pero aún así, ¿no era Borges ya en los 40 un autor conocido no solamente en Argentina, sino en Latinoamérica? y ¿no fue traducido al francés ya en los años 30 en adelante? ¿Y cuánto tuvo que esperar Kafka? Y Pavlovsky ha sido marginado por muchos años por el oficialismo teatral y por la crítica de su propio país, y a pesar de todo su teatro comienza, se desplaza y expande y hoy pasa a ser materia académica, y lo digo con gran gusto, ya que fuera de esa miscelánea con el título El teatro argentino hoy (publicada en Buenos Aires en Ediciones Búsqueda en 1981), los artículos científicos o una crítica universitaria seria, eran hasta comienzo de los años 90 prácticamente inexistentes ${ }^{5}$; esto ha cambiado desde entonces

5 Pellettieri (1990) en su libro sobre Cien años de teatro argentino. De Moreira a Teatro Abierto no menciona a Pavlovsky, en su siguiente trabajo, Teatro argentino contemporáneo (1980-1990). Crisis, transición y cambio (1994: 66-72), le dedica 9 páginas bajo el despectivo título de "Paso de dos [...] un texto dramático remanente y una puesta eficaz" y describe la puesta como "tradicional de mentalidad convencionalizadora de los ideales del teatro indepen- 
considerablemente. Una gran diferencia existe aún entre ambos creadores, mientras la obra de Borges ha sido a más tardar desde los años 60 objeto de infinidades de estudios con un altísimo nivel, el teatro de Pavlovsky comienza a conquistar poco a poco ese espacio internacional, global.

El "arte menor" de Borges y de Pavlovsky es una creación subversiva, semiótica y culturalmente revolucionaria dentro de los grandes cánones y que luego pasa a ser paradigmática, pero es difícilmente una literatura/un teatro para todos. Hacer "arte menor" significa en Borges y en Pavlovsky (como en Kafka) la forma en que se desarrolla su escritura y performancia dentro del estándar, una literatura o teatro menor con un lenguaje y con temas fuera del contexto, en el más allá de 'Oriente', una literatura/un teatro inclasificable y no contextualizable con las grandes corrientes. Se trata de una constante desterritorialización, es decir, de la imposibilidad de Borges/ Pavlovsky de escribir/representar en ese castellano, en esa forma rioplatense, inglesa, francesa o alemana. En esta fisura, Borges y Pavlovsky fundan/pliegan sus lenguajes, sus poéticas y sus temas. Ya en Evaristo Carriego o en Último Match o Mueca comienzan a deconstruir su contorno: uno toma un poeta popular porque era “amigo y vecino", “casi invisible” (Borges 1970/1999: 84-85) y "cuanto más escribía, menos [le] importaba [su] héroe” (ibíd.: 86); el otro la figura del boxeador, de las masas ávidas de violencia. Ambos parten de los marginados, de un lugar de la periferia de Buenos Aires, de los "tristes arrabales": Borges parte de un autor que muere a los vientinueve años y deja una sola obra; durante el proceso de escritura la persona de Carriego desaparece cediendo el espacio a la metrópolis de Buenos Aires ("Había empezado a hacer una simple biografía, pero a mitad de camino me empezó a interesar cada vez más el viejo Buenos Aires"; ibíd.: 86). He aquí el aspecto deconstruccionista, desterritorializador, desplazador y orientalizador, de negociación de la escritura de Borges y de Pavlovsky que niegan el origen como categoría esclavizante.

Tanto la creación de Borges como la de Pavlovsky es de carácter altamente política, si este término se entiende semiológicamente y dentro del concepto de "arte menor". El hecho mismo de reubicar los márgenes, lo menor (la fisura), el quebrar con cánones de todo tipo -por ejemplo la postura con respecto al judaísmo y al nazismo de Borges, o aquella de Pavlovsky (en: ídem/A. de Toro 1991: 43) que dice: "Mis contenidos son una forma de tratar la política, no son política"-, hace de un acto literario individual, un acto subversivo, revolucionario, así como de un microcosmos, un macrocosmos. De ahí que, por otra parte, el individualismo minoritario de la

diente histórico argentino y del realismo de los 60". Se identifica con el "teatro serio", portador de una alta referencialidad, de "tesis realista", de un "realismo reflexivo", "texto epigonal", de "medianía autorial"; por otra parte, los personajes son -según él- contradictorios de pronto "simbólicos", "expresionistas", "desrealizados", es un "teatro redundante". Este tipo de crítica es realmente redundante, ya que es de tipo periódica-valorizante y no de orientación académica y refleja un profundo desconocimiento del objeto teatral actual y desconoce asimismo el manejo de términos académicos archiconocidos como 'realismo', 'expresionismo', 'simbolismo', etc. 
literatura de Borges represente un acto colectivo, ya que evoca la abolición de jerarquías, anuncia la muerte del autor (introducción de la dialogicidad palimpsesta múltiple y nómada), la diversidad de narradores (como en "El inmortal"), anula el centro, se desvía de cualquier norma. Pavlovsky, a su vez, elabora la "complejidad del personaje del torturador, de adentro, y no la mera denuncia, "he representado lo que siente este individuo [...]" (ibíd.). El hecho de que Borges y Pavlovsky se encuentren en la fisura de culturas y concepciones literario-teatrales, los pone en una situación frágil, siempre oscilante y los lleva a formar otra sensibilidad literaria. Por esto, como hemos descrito en otros trabajos (por ejemplo en A. de Toro 1992, 1994, 1994a,), lo citado o evocado jamás se produce en su forma originaria, no nos lleva ni a un sujeto de la enunciación ni a un enunciado que afirme el resultado final, así por ejemplo, en "Tlön, Uqbar, Orbis Tertius" o en "Pierre Menard" (donde el Quijote no es más el Quijote), en Pablos, Potestad (véase foto 13, pág. 543), Paso de Dos, Poroto y La muerte de Margarite Duras.

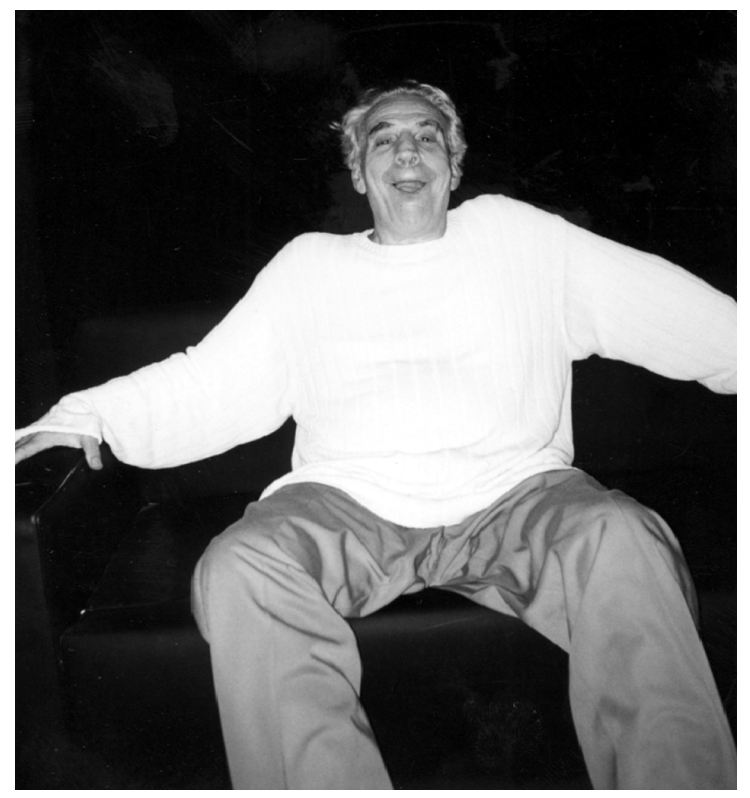

Pavlovsky en La muerte de Marguerite Duras

(C) Foto de Alfonso de Toro 
El excursionar en la fisura, en el pliegue no es algo sustancial ni a Borges ni a Pavlovsky, como tampoco lo es el hecho de habitar Buenos Aires, sino a cualquier autor que comparta la misma actitud intelectual, no es algo inherente a la periferia como lo demuestran Deleuze/Guattari con respecto a Kafka. La 'literatura menor' es un tipo particular de literatura o de teatro, de cultura al fin, algo que se podría entender con Barthes como "texte scriptible" (cfr. A. de Toro 1999: 146-148), como un texto cartográfico de infinitas entradas y salidas:

[...] c'est nous en train d'écrire, avant que le jeu infini du monde (le monde comme jeu) ne soit traversé, coupé, arrêté, plastifié par quelque système singulier (Idéologie, Genre, Critique) qui en rabatte sur la pluralité des entrées, l'ouverture des réseaux, l'infini des langages. (Barthes 1970: 11)

$[\ldots]$

Dans ce texte idéal, les réseaux sont multiples et jouent entre eux, sans qu'aucun puisse coiffer les autres; ce texte est une galaxie de signifiants, non une structure de signifiés; il n'a pas de commencement; il est réversible; on y accède par plusieurs entrées dont aucune ne peut être à coup sûr déclarée principale; les codes qu'il mobilise se profilent $\grave{a}$ perte de vue? ils sont indécidables [...]; de ce texte absolument pluriel, les systèmes de sens peuvent s'emparer, mais leur nombre n'est jamais clos, ayant pour mesure l'infini du langage. (ibíd.: 12)

Con palabras de Deleuze/Guattari (1975: 33):

Même celui qui a le malheur de naître dans le pays d'une grande littérature doit écrire dans la langue, comme un juif tchèque écrit en allemand, ou comme un Ouzbek écrit en russe. Écrire comme un chien qui fait son trou, un rat qui fait son terrier. Et, pour cela, trouver son propre point de sous-développement, son propre patois, son tiers monde à soi, son désert à soi.

Borges y Pavlovsky producen su 'patois', su tiers monde, su désert, es decir, su 'Oriente' y se encuentra, por una parte, dentro de la gran tradición de la literatura y teatro europeo. A esta tradición se suma el contexto de la literatura argentina que está formando aún su tradición y serán Borges y Pavlovsky los que finalmente la funden. Borges y Pavlovsky sienten que aún no viven, ni escriben, ni representan en su propia lengua. Por eso intentan al comienzo encontrar su propio lugar "entre" las tradiciones y no contra ellas, por deconstrucción, es decir, a través de un proceso continuo de desterritorialización y reterritorialización, de 'pliegue'. Borges y Pavlovsky emprenden la desterritorialización (un viaje semiótico), que en base a procedimientos tales como 'pliegue' y 'repliegue', 'traza' sin origen ni fin, 'lazo' sin arriba ni abajo conducen a una "literatura menor", a una literatura de la altaridad, a una literatura de fisura. Para esto Borges y Pavlovsky se valen de algunos autores que les permiten desprenderse de la mimesis (como Carlyle, De Quincey, Meinong, Bradley, Butler, W. James, Russell, Schopenhauer, Jarry, Artaud, Beckett e Ionesco) o de otros casi invisibles - como Evaristo Carriego- o de algunos temas del arrabal... Borges y Pavlovsky escriben el desierto, escriben una página y representan en un espacio vacío 
bajo los cuales se encuentra un palimpsesto que es destemporalizado y trastocado en el espacio. Borges y Pavlovsky logran su desierto, su "tercer mundo", su "cuarta dimensión", su 'Oriente', se ubican más allá del texto (cfr. A. de Toro 1999). Borges y Pavlovsky se transforman en un emigrante e inmigrante, en "[...] un judío [al que] siempre le será más fácil que a un occidental no judío innovar en la cultura occidental", en uno de "[...] muchos de esos irlandeses ilustres (Shaw, Berkeley, Swift) [que] fueron descendientes de ingleses" (OC I: 272-274). Borges habla aquí del "sentimiento" de sentirse algo y de todos modos ser un nómada, con lo cual se ubica "en medio" en un estado "unhomely" (Bhabha 1994), en una patria que está en todos los lugares, que resiste lo propio y lo extraño, donde identidad/escritura/cultura/discurso son categorías por negociar. Esto no representa ni para Borges ni para Pavlovsky un conflicto - como ya indicábamos-, sino más bien la decisión que literatura, el teatro y cultura, el pensamiento en su totalidad, solamente son transformables, renovables en un proceso de altaridad, en una infinita traza, en esa "postergación infinita" o en ese "regressus in infinitum" (Borges 1982: 9, 10, 19; cfr. también A. de Toro 1999a), en una literatura como la de Kafka que "[...] trasciende el momento en que se escribió [...] y ahí está su valor" (Borges 1983: 3) o la recurrencia retórica y gestual, la economía y la estética del "dintel" (Pavlovsky en una conversación, Buenos Aires, abril 1999) o de la ausencia.

Otra característica de la escritura de Borges y de la escritura y representación de Pavlovsky es su sobriedad, su economía, su transparencia, su austeridad, que al primero le costó el reproche de "pobre erudición", donde solamente la intensidad, el sentimiento vale, y al segundo la crítica de epigonal y mediocre. Borges y Pavlovsky enfilan su literatura y teatro para llegar a ser nómadas e inmigrantes en su patria, en el mundo, para ser un judío y un gitano literario o teatral. Borges y Pavlovsky son extranjeros en su propia lengua y cultura, son universales, argentinos, rioplatenses. El lenguaje de ambos no es el mismo de su lugar, sus creaciones no son las de los otros, son diferentes. Sus creaciones son siempre 'para'-lenguaje, 'para'-literatura, 'para'filosofía, 'para'-teatro..., son la tensión constante de la diferencia, reunida en la altaridad. Su escritura lleva los lexemas y la representabilidad a una disonancia, a acordes disonantes de donde se desprende una tensión, una intensidad particular, todo estalla, pone acentos y sonidos que bajo su superficie ofrecen una deformación: una fisura. Y como Deleuze/Guattari apuntan: en autores de "literatura menor" -como también lo son en este caso Borges y Pavlovsky-, la langue cesse d'être représentative pour tendre vers ses extrêmes ou ses limites (1975: 42). En la literatura de Borges y en el teatro de Pavlovsky tenemos la confluencia de cuatro tipos de lenguajes:

- la lengua materna, regional, el lenguaje del hic et nunc: el castellano;

- la lengua urbana, mundial, estándar: el inglés;

- la lengua referencial, cultural, literaria;

- la lengua mítica, literaria, artística que se construye más allá, en la altaridad. 
Borges y Pavlovsky hacen rodar estas diferentes lenguas con sus diferentes funciones, cada una traspasa sus límites, se confunden las unas con las otras: "inbetween", así ambos autores terminan con las dicotomías, con el logocentrismo, con el dualismo, crean sus lenguas, sus literaturas, su teatro; son únicas, irrepetibles, inclasificables, están siempre deslizándose.

Para concluir agregamos algunos ejemplos, en particular sobre Pavlovsky, para la ilustración de los términos 'literatura menor' y 'Oriente'. Borges y Pavlovsky optan por la literatura menor, por las 'orillas' o por el 'Oriente' en un sentido semiótico y epistemológico, esto es, se ubican ‘in-between' (Bhabha). Oriente es el lugar noescrito, la página blanca no conquistada, colonizada, mimetizada que les permite desterritorializar y territorializar los signos. Cuando, por ejemplo, Borges en "El Jardín de senderos que se bifurcan" habla de un laberinto que es una novela china que se encuentra en una biblioteca de "libros orientales y occidentales" (OC I: 476), la mirada o lectura de Borges no va al 'oriente' como a algo exótico, anecdótico, sino al laberinto infinito de tipo sígnico atemporal ("Crea, así diversos porvenires, diversos tiempos, que también proliferan y se bifurcan"; $O C$ I: 478). El laberinto chino pasa de una categoría topográfico-cultural, a una sígnico-epistemológico-cultural, que le permite desterritorializar el concepto de lo 'chino' como concepto de un oriente extraño, de lo diferente, como el de lo occidental entendido como lo habitual. El laberinto de la novela de Ts'ui Pên es hermética tanto para Yu Tsun como para Albert, mas este último logra descubrir que se trata de un concepto de laberintos que va más allá del tradicional. La obra es una contradicción, no es clasificable y se substrae a una tradición determinada y al canon que pretende una trayectoria de siglo a siglo, de diversas refundiciones significantes, a un laberinto con una entrada y una salida, con una arquitectura descifrable:

Imaginé también una obra platónica, hereditaria, trasmitida de padre a hijo, en la que cada nuevo individuo agregara un capítulo o corrigiera con piadoso cuidado la página de los mayores. Esas conjeturas me distrajeron; pero ninguna perecía corresponder, siquiera de un modo remoto, a los contradictorios capítulos de Ts'ui Pên. (OC I: 477)

En Pablos, Pavlovsky habla de una "letra final [...] no escrita", donde la letra final es "letra de puesta", la letra es "imagen que recrea otro discurso al ser mirada" que "dará lugar a otras escenas, inscritas sólo como posibilidad de texto" y agrega su concepción del texto dramático como "búsqueda" que se desprende del rigorismo tradicional dando la impresión de anarquía de la estructura. Pero para Pavlovsky la estructura "es una malla del lenguaje del texto escrito", es decir, inscrita a una estructura que se concretiza en el texto espectacular. Es un texto con "vacíos", un texto que debe ser transgredido. No se trata de una re-escritura del texto, sino de una perlaboración, en el lenguaje de Pavlovsky, de "[reinscribirlo] de múltiples sentidos, aprisionados en el texto original” (vid. Pavlovsky 1986: 54-55).

El personaje Pablo es una mera mención, un grafema, sin rostro, sin pasado explicado, sin identidad y sin función, como así también aquella de los otros dos perso- 
najes, L. y V. Sin embargo, Pablo parece unir a tres personajes, a los dos mencionados y a Irina que tiene, por lo visto, una vaga relación con V. Ellos crean su "patois".

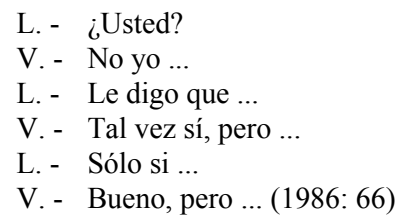

Sabemos que V. un buen día visita a L. diciéndole que viene de parte de Pablo, le extiende una carta que lleva junto con una valija y una fumigadora. El lugar donde se encuentra L. es anónimo, es el 'Oriente', lo mismo ocurre con el lugar de donde proviene V. y tampoco se llega a saber si L. era realmente amigo de Pablo como sostiene $\mathrm{V}$. Lo único que sacamos en claro son los siguientes puntos:

- la predominancia del tema de que "las cosas allá se amontonan por todas partes; problemas de abundancia" vs. "acá nada sobra, falta";

- todo lo que recuerda V. de "acá" no es confirmado por L.:

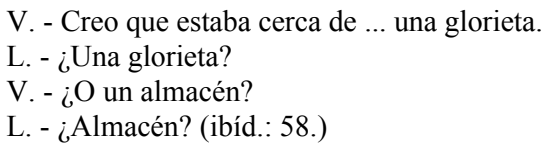

'Allá'/‘acá' son índices de lo deshabitado y por habitar, no configuran nignún lugar, sino la ausencia de lugar que lleva a la refutación de las espectaciones tradicionales de teatro. En cuanto a la pregunta de L. “¿Y ahora qué pasa?” (observando la escena entre el viejo y la mujer joven), V. responde:

Nada, qué quiere que pase. Se están estudiando. Usted quiere cosas concretas. Acontecimientos visibles. Trazo grueso. Son la generación del trazo grueso. Nosotros vemos lo invisible. Nos hemos acostumbrado a lo imperceptible. Lo grueso es lo que sobra. Tenemos que reinventar todo. (ibíd.: 75)

A las 'cosas concretas' y al 'trazo grueso' se le oponen 'lo invisible', lo 'imperceptible’ que requieren una reinvención, una recodificación de una posición de la fisura, de 'entremedio'. La solución es la simulación:

Él simula que se quiere levantar y ella simula que lo va a ayudar. Se suspende la imagen.

$[\ldots]$

L. - Son los pequeños gestos los que interesan. Lo imperceptible. En esos pequeños gestos donde el viejo encuentra sus actos de libertad [...].

$[\ldots]$ 
Pero también de los disfraces, juegos de palabras, máscaras infinitas, retórica, vacío, de un vacío que vuelve a ser máscara ... de tantas trampas ... sólo se construye una mueca, que dice:

$[\ldots]$

(Irina hace gestos en silencio con la boca [...]). (ibíd.: 73, 74, 87)

Ambos autores tratan así exitosamente de escapar de la mimesis, de escapar del canon, se trata de la construcción "de un laberinto de laberintos" (OC I: 475), infinito donde "todos los desenlaces ocurren; cada uno es el punto de partida de otras bifurcaciones" (ibíd.: 478). Ts'ui Pên es un hombre de cultura y de pensamiento altamente híbrido: es un pensador, literato, aficionado a la metafísica y a la mística, así también a la "controversia filosófica" (ibíd.), de allí lo indefinible de su texto. En Pavlovsky ello está representado por los "disfraces, juegos de palabras, máscaras infinitas, retórica, vacío, de un vacío que vuelve a ser máscara ... de tantas trampas ... sólo se construye una mueca".

Aquí también es importante destacar que los libros occidentales no se encuentran en la biblioteca en oposición, en conflicto con los libros orientales, no es Yu Tsun (experto en laberintos) el que descifra el libro, sino Albert. La mirada hacia 'Oriente' o la lectura de éste comienza a transformar su pensamiento que va de un logos marcado por una lógica topográfica, binarista, mimética a una estructura rizomática a-temporal. Albert entra en una negociación de su identidad, de su conocimiento con el 'Oriente' y lo reterritorializa en su propia cultura. Así, Borges supera el binarismo atávico de identidades aparente y tradicionalmente extrañas y excluyentes.

Otro breve ejemplo lo encontramos en "Tlön, Uqbar, Orbis Tertius" donde Borges sitúa Uqbar en una enciclopedia imaginada (es decir, fuera de contexto, fuera de territorio, donde ésta se debe reconstruir) y que escapa a cualquier topografía geográfica ("[...] la Erdkunde de Ritter ignoraba con plenitud el nombre de Uqbar"; $O C$ I: 432) y allí, en la enciclopedia la pone en frontera con Jorasán, Armenia y Erzerum pero solamente en forma "ambigua" (ibíd.). La región de Uqbar existe en el 'pliegue', en la 'fisura' solamente en esa enciclopedia imaginada. El texto sobre esta región es similar al de Ts'ui Pên: "[...] escritura [de una] fundamental vaguedad", "[...] nebulosos puntos de referencias [...]", se caracteriza por una literatura fantástica que se refiere solamente a "[...] regiones imaginarias de Mlejnas y Tlön" (OC I: 432). Este artículo de la enciclopedia es luego cubierto palimsésticamente por un laberinto de otros textos que figuran en la bibliografía agregada al final del artículo en una mezcla de textos inventados y de autores reales o de ambos inventados y reales. Borges elige el 'Oriente' como un lugar de perlaboración de la cultura y del pensamiento.

Eduardo Pavlovsky crea su lenguaje propio ya en Último Match cuando el triunfo del campeón que mata a su rival finaliza en su propia auto-inmolación, en el suicidio que es contextualizado como un triunfo frente a la masa del público que reclama otro Campeón. Así, Pavlovsky invierte desde la orilla los parámetros de la violencia deportiva. Los lugares tales como el 'estadio', la 'calle', la 'habitación del campeón', el 'gimnasio', la 'plaza de ciudad', la 'antesala de un alto funcionario' y la 
'noche cerrada y un árbol', son desterritorializados y reterrorializados en un espacio de la conciencia reducida del Campeón hasta el enmudecimiento y pérdida de identidad. El Campéon es mostrado en su fatal ambigüedad de victimario y víctima, como una máquina de violencia y como un personaje débil, sensible, lleno de contradicciones. Pavlovsky y Hermes despojan la obra de su carga 'realista', 'expresionista' o meramente 'anecdótica', 'mensajista' y moralista, muestran por el contrario los abismos de la 'fisura'. O en Cámara lenta. Historia de una cara nuevamente se trata de la vida de un boxeador, mejor dicho de un ex-boxeador, su manager y una prostituta amiga de ambos, donde Pavlovsky traza un diagrama de las desviaciones alucinantes del boxeador quien por un lado ama en forma fetichista los pies de la prostituta y por otro es invadido por una crueldad criminal frente sus contraentes. En La Mueca como en Cerca. Melodía inconclusa de una pareja, se sitúa Pavlovsky en la fisura que conecta la soledad, la tortura y el amor, el criminal y la víctima, el poder y la opresión, la verdad y la mentira tanto en un nivel individual como en un nivel colectivo o familiar (de igual forma ocurre en Telarañas). Todas estas obras hacen visible la estructura ideológica invisible que subyace en toda relación social. A estas temáticas se agrega la de la angustia, común denominador de muchas obras, en particular en su forma anónimo-despótico (por ejemplo en El señor Galíndez).

Desafiante es la aparente forma cruda, indolente, indiferente y neutral en que se tratan los campos tabúes como masoquismo, sadomasoquismo y sadismo en las relaciones y acciones humanas, donde el bacanal dionisíaco se mezcla con sangrientas torturas y la liquidación del otro: eros y tánatos estrechamente entrelazados.

\section{RESUMEN}

Eduardo Pavlovsky crea un teatro de las 'orillas' en el sentido de arte 'menor'. Se ubica en la fisura de las tradiciones e innovaciones, de lo local cotidiano y de lo universal, enmedio de las oposiciones, superándolas a través de una estrategia de hibridización, haciendo trascender sus propuestas y partiendo de todo aquello que lo circunda. Esto le permite producir una radiografía implacable de nuestra condición actual histórica y antropológica en general. 


\section{BIBLIOGRAFÍA}

\section{Obras}

Borges, Jorge Luis. (1970/1999). Autobiografía. Buenos Aires: El Ateneo.

----. (1982). “Jorge Luis Borges habla del mundo de Kafka”, en: Franz Kafka. La metamorfosis. (traducción de Nélida Mendilaharzu de Machain). Buenos Aires: Ediciones Orion. pp. 5-28.

----. (1983). "Suplemento Centenario del nacimiento de Franz Kafka”, en: El País (3 de julio): 3 .

----. (1989). Obras Completas. Vol. I-III. Buenos Aires: Emecé Editores.

Pavlovsky, Eduardo. (1970/1970*). Último Match. (en trabajo conjunto con Juan Carlos Hermes). Buenos Aires: Ediciones Búsqueda.

----. (1976/1976*). Telarañas. Buenos Aires: Ediciones Búsqueda. También: (1980). Madrid: Editorial Fundamentos.

----. $\left({ }^{1} 1978 /{ }^{2} 1987 / 1981^{*}\right)$. Cámara lenta. Historia de una cara. Buenos Aires: Ediciones Búsqueda. También: (1989). Madrid: Editorial Fundamentos.

----. (1980/1971*). La mueca. Madrid: Editorial Fundamentos. También: (1988). Buenos Aires: Ediciones Búsqueda.

----. (1980/1973). El señor Galíndez. Madrid: Editorial Fundamentos. También: (1986). Buenos Aires: Ediciones Búsqueda.

----. (1982/1983*). El señor Laforgue. Buenos Aires: Ediciones Búsqueda. También: (1989). Madrid: Editorial Fundamentos.

----. (1986/1987*). Pablo. Buenos Aires: Ediciones Búsqueda. También: (1989). Madrid: Editorial Fundamentos.

----. (1987/1985*). Potestad. Buenos Aires: Ediciones Búsqueda. También: (1989). Madrid: Editorial Fundamentos.

----. (1988). Cerca. Buenos Aires: Ediciones Búsqueda.

----. (1989/21990/1990*). Paso de Dos. Buenos Aires: Ediciones Búsqueda/Ayllu.

----. (1992). El Cardenal. Buenos Aires: Ediciones Búsqueda.

----. (1994/1994*). Rojos globos rojos. Buenos Aires: Ediciones Babilonia.

---- (1999/1998*). Poroto. Nueva versión para teatro. Buenos Aires: GalernaBúsqueda de Ayllu.

----. (2000/2000*). La muerte de Marguerite Duras. Manuscrito inédito.

\footnotetext{
* Indicamos con un asterisco la fecha de la primera puesta en escena de la obra respectiva. La otra fecha se refiere al año de publicación de la misma.
} 


\section{Crítica}

Angehrn, Claudia. (2004). Territorium Theater, Körper, Macht, Sexualität und Begehren im dramatischen Werk von Eduardo Pavlovsky (Theorie und Praxis des Theaters). Frankfurt am Main: Vervuert.

Barthes, Roland. (1970). S/Z. Paris: Seuil.

Bhabha, Homi. (1994). The Location of Culture. London/New York: Routledge.

Baudrillard, Jean. (1981). Simulacre et Simulation. Paris: Galilée.

Deleuze, Gilles/Félix Guattari. (1975). Kafka. Pour une littérature mineure. Paris: Minuit.

----. (1976). Rhizom. Paris: Minuit.

----. (1988). Le pli. Leibniz et le baroque. Paris: Minuit.

Derrida, Jacques. (1967). L'écriture et la différence. Paris: Seuil.

----. (1968). "La différance", en: Théorie d'ensemble. Paris: Seuil. pp. 42-66.

---.. (1972). La dissémination. Paris: Seuil.

Ferrigno, Oscar. (1980). "Prólogo", en: Eduardo Pavlovsky. La mueca. Madrid: Editorial Fundamentos. pp. 25-26.

Hegel, Georg Wilhelm Friedrich. (1801/1981). Differenz des Fichteschen und Schellingschen Systems der Philosophie. Leipzig: Reclam.

Lacan, Jacques. (1964/1973). "La ligne et la lumière", en: ídem. Le séminaire de Jacques Lacan. Livre XI. Les quatre concepts fondamentaux de la psychoanalyse. 1964. (texte établi par Jacques-Alain Miller). Paris: Seuil. pp. 85-96.

----. (1966). Écrits I. Paris: Seuil/Points.

----. (1978). "Linie und Licht", en: ídem. Das Seminar von Jacques Lacan. Buch XI (1964). Die Vier Grundbegriffe der Psychoanalyse. (übersetzt von Norbert Hass). Otten/Freiburg im Breisgau: Walter-Verlag. pp. 97-111.

Olea Franco, Rafael. (1993). El otro Borges. El primer Borges. Buenos Aires: Fondo de Cultura Económica.

Pavlovsky, Eduardo. (1980). "Reflexiones sobre el proceso creador", en: ídem. La тиеса/El señor Galíndez/Telarañas. Madrid: Editorial Fundamentos. pp. 181188.

----. (1980a). "Algunos conceptos sobre el teatro de vanguardia", en: ídem. $L a$ тиеса/El señor Galíndez/Telarañas. Madrid: Editorial Fundamentos. pp. 189196.

----. (1980b). "Prólogo", en: ídem. Telarañas. Madrid: Editorial Fundamentos. pp. $125-126$.

----. (1986). “Apuntes para una obra de teatro”, en: ídem. Pablos. Buenos Aires: Ediciones Búsqueda. pp. 54-55. 
---- (1987): "Prólogo", en: ídem. Potestad. Buenos Aires: Ediciones Búsqueda. pp. 13-17.

----. (1987a). "Balbuceo del proceso creativo", en: ídem. Potestad. Buenos Aires: Ediciones Búsqueda. pp. 15-17.

----. (1989)“Paso de Dos. Aventura de una puesta”, en: ídem. Paso de Dos. Buenos Aires: Ediciones Búsqueda/Ayllu. pp. 31-39.

---- Juan Carlos Hermes. (1970). "Notas", en: ídem. Último Match. Buenos Aires: Talía. pp. 3-4.

---- Jaime Kogan. (1986). "Introducción”, en: Eduardo Pavlovsky. El señor Galíndez. Buenos Aires: Ediciones Búsqueda. pp. 9-11.

---- /Alfonso de Toro. (1991). "Eduardo Pavlovsky: El teatro del goce y los nuevos territorios existenciales", (entrevista), en: La Escena Latinoamericana, 7: 42-45.

Pellettieri, Osvaldo. (1990). Cien años de teatro argentino. De Moreira a Teatro Abierto. Buenos Aires: Editorial Galerna y IITCTL.

----. (1994). Teatro argentino contemporáneo (1980-1990). Crisis, transición y cambio. Buenos Aires: Editorial Galerna.

Sarlo, Beatriz. (1993/1995). Borges un escritor en las orillas. Buenos Aires: Verso.

Taylor, Mark C. (1987). Altarity. Chicago: The University of Chicago Press.

Toro, Alfonso de. (1990). "Semiosis teatral postmoderna: intento de un modelo", en: Gestos, año 5, 9: 23-52.

----. (1991). "Entre el teatro kinésico y el teatro deconstruccionista: Eduardo Pavlovsky", en: La Escena Latinoamericana, 7: 1-3.

----. (1991a). "Cambio de paradigma: el 'nuevo' teatro latinoamericano o la constitución de la postmodernidad espectacular", en: Iberoamericana, 43/44, año 15, 23: 70-92. Reimpreso en: (1991b). Espacio, año 5, núm. 9: 111-133.

----. (1992). 'El productor 'rizomórfico' y el lector como 'detective literario': la aventura de los signos o la postmodernidad del discurso borgesiano (intertextualidad-palimpsesto-rizoma-deconstrucción)", en: Karl Alfred Blüher/ídem (eds.). Jorge Luis Borges. Procedimientos literarios y bases epistemológicas. Frankfurt a. M./Madrid: Vervuert/Iberoamericana. pp. 145-183.

----. (1994). "Borges y la 'simulación rizomática dirigida': percepción y objetivación de los signos", en: Iberoamericana, 18, 1, 53: 5-32.

----. (1995). "Jorge Luis Borges. The Periphery at the Center/The Periphery as Center/The Center of the Periphery: Postcoloniality and Postmodernity", en: Fernando de Toro/ídem (eds.). Borders and Margins: Post-Colonialism and Post-Modernism. Frankfurt a. M./Madrid: Vervuert/Iberoamericana. pp. 11-45. En español: (1996). "Postcolonialidad, Postmodernidad y Jorge Luis Borges. La periferia en el centro -la periferia como centro- el centro de la periferia: postcolonialidad y postmodernidad", en: Iberoromania, 44, 2: 64-98. 
----. (1996a). "Das postmoderne Theater von Eduardo Pavlovsky", en: Maske \& Kothurn, 1: 67-92.

----. (1996b). "El teatro postmoderno de Eduardo Pavlovsky", en: ídem/Klaus Pörtl (eds.). Variaciones sobre el teatro latinoamericano. Tendencias y perspectivas. Frankfurt a. M./Madrid: Vervuert/Iberoamericana. pp. 59-84.

----. (1999). "Borges/Derrida/Foucault: Pharmakeus/Heterotopia o más allá de la literatura ('hors-littérature'): escritura, fantasmas, simulacros, máscaras, carnaval y... Atlön/Tlön, Ykva/Uqbar, Hlaer, Jangr, Hrön(n)/Hrönir, Ur y otras cifras”, en: ídem/Fernando de Toro (eds.). Jorge Luis Borges. Pensamiento y Saber en el siglo XX. Frankfurt a. M./Madrid: Vervuert/Iberoamericana. pp. 139-163. En inglés: (1999a). "Borges/Derrida/Foucault: Pharmakeus/Heterotopia or beyond Literature ('hors-littérature'): Writing, Phantoms, Simulacra, Masks, the Carnival and ... Atlön/Tlön, Ykva/Uqbar, Hlaer, Jangr, Hrön(n)/Hrönir, Ur and Other Figures", en: ídem/ Fernando de Toro (eds.). Jorge Luis Borges. The Thought and the Knowledge in the Twentieth Century. Frankfurt a. M./Madrid: Vervuert/Iberoamericana. pp. 129-153.

----. (2000). "La realidad como viaje a través de los signos: Cervantes, Borges, Foucault", en: ídem/Suzanna Regazzoni (eds.). El siglo de Borges. Literatura Ciencia - Filosofía. Frankfurt a. M./Madrid: Vervuert/Iberoamericana. pp. 4565.

----. (2001). "La "literatura menor", concepción borgesiana del 'Oriente' y el juego con las referencias. Algunos problemas de nuevas tendencias en la investigación de la obra de Borges", en: Revista Iberoromania, 53: 31-77.

---- /Fernando de Toro (eds.). (1998) Acercamientos al teatro actual. (1975-1995). Historia - Teoría - Práctica. Frankfurt a. M./Madrid: Vervuert/Iberoamericana.

Toro, Fernando de. (1995). "From Where to speak? Postmodern/Postcolonial Positionalities", en: ídem/Alfonso de Toro (eds.). Borders and Margins: Post-Colonialism/Post-Modernism. Frankfurt am Main: Vervuert. pp. 131-148.

----. (1999). "Borges/Derrida y la escritura”, en: Alfonso de Toro/ídem (eds.). Jorge Luis Borges. Pensamiento y saber en el siglo XX. Frankfurt a. M./Madrid: Vervuert/Iberoamericana. pp. 125-138. 